\title{
The Efficient Market Hypothesis: Empirical Evidence
}

\author{
Martin Sewell ${ }^{1}$ \\ ${ }^{1}$ Faculty of Economics, University of Cambridge, Cambridge, United Kingdom \\ Correspondence: Martin Sewell, Faculty of Economics, University of Cambridge, Sidgwick Avenue, Cambridge \\ CB3 9DD, United Kingdom. Tel: 44-797-414-5461. E-mail: mvs25@cam.ac.uk
}

Received: June 6, 2012 Accepted: August 3, 2012 Online Published: October 17, 2012

doi:10.5539/ijsp.v1n2p164 URL: http://dx.doi.org/10.5539/ijsp.v1n2p164

\begin{abstract}
The efficient market hypothesis (EMH) has been the central proposition of finance since the early 1970s and is one of the most well-studied hypotheses in all the social sciences, yet, surprisingly, there is still no consensus, even among financial economists, as to whether the EMH holds. Five statistical analyses are conducted in an attempt to explicate such apparently contrary convictions. An analysis of daily, weekly, monthly and annual Dow Jones Industrial Average log returns found that first-order autocorrelation is small but positive for all time periods, with the autocorrelations for daily and weekly returns closest to zero, and thus an efficient market. A standard runs test showed that the hypothesis of independence is strongly rejected for daily returns, but accepted for weekly, monthly and annual returns, whilst the results of a more sophisticated runs test showed that daily, weekly and decreasing returns are the least consistent with an efficient market. Rescaled range analysis was conducted on the same data sets, and there was no significant evidence for the existence of long memory in the returns, a result consistent with market efficiency. Finally, from an analysis of investment newsletters it may be concluded that technical analysisas applied by practitioners - fails to outperform the market. I reconcile the fact that daily stock market log returns pass linear statistical tests of efficiency, yet non-linear forecasting methods can still generate above-average riskadjusted returns, whilst discretionary technical analysts fail to make abnormal returns.
\end{abstract}

Keywords: efficient market hypothesis, Dow Jones Industrial Average, dependence, autocorrelation, runs test, long memory, investment newsletters

\section{Introduction}

Just over a decade ago Mark Rubinstein published 'Rational markets: Yes or no? The affirmative case' in the Financial Analysts Journal (Rubinstein, 2001). The current article lends empirical support to the validity of the question, and provides a more complex answer. The central paradigm in finance is the 'efficient market hypothesis', which is covered in the following section. This paper describes five pieces of research, each of the first four analyse daily, weekly, monthly and annual data from a major US stock market index. The first and most straightforward test is a measurement of the autocorrelation of stock market returns. The second and third investigations involve a simple and an advanced version of the runs test (a non-parametric statistical test of the mutual dependence of the elements of a sequence). The fourth investigation tests for the existence of long memory. Finally, the fifth piece of work involves an analysis of the performance of investment newsletters. All five analyses (potentially) have implications apropos market efficiency.

\section{Efficient Market Hypothesis}

The efficient market hypothesis (EMH) has been the central proposition of finance since the early 1970s and is one of the most controversial and well-studied propositions in all the social sciences. Despite improvements in the quality and quantity of data, advances in statistical analysis and improvements in theoretical models, there is little consensus among financial economists as to the validity of the EMH. For example, just under half of the papers reviewed in Sewell (2011) support market efficiency.

A market is said to be efficient with respect to an information set if the price 'fully reflects' that information set (Fama, 1970), i.e. if the price would be unaffected by revealing the information set to all market participants (Malkiel, 1992). The classic taxonomy of information sets, due to Roberts (1967) and published by Fama (1970), consists of the following:

weak form efficiency The information set includes only the history of prices. 
semi-strong form efficiency The information set includes all information known to all market participants (publicly available information).

strong form efficiency The information set includes all information known to any market participant (private information).

Note that the sets are nested, with each successive set being a superset of the preceding set. Later, the weak form was redefined by Fama (1991) to include variables like dividend yields and interest rates. The first four analyses in this article test for weak form efficiency, and the fifth piece of work, involving investment newsletters, tests for both weak form efficiency and semi-strong form efficiency.

It has been argued that the EMH is both untestable and impossible. An efficient market will always 'fully reflect' available information, but in order to determine how the market should 'fully reflect' this information, it is necessary to determine investors' risk preferences. Therefore, any test of the EMH is a test of both market efficiency and investors' risk preferences. For this reason, the EMH, by itself, is not a well-defined and empirically refutable hypothesis. This ‘joint hypothesis problem' was first pointed out by Fama (1970). Whilst Beja (1977), (most importantly) Grossman and Stiglitz (1980) and Tirole (1982) argued that because information is costly, prices cannot perfectly reflect the information which is available, since if this was the case, those who spent resources to obtain it would receive no compensation, leading to the conclusion that an informationally-efficient market is impossible.

Consider a market and a tradable asset. If one could be sure that the price of the asset will rise tomorrow, the asset would be bought today, raising the price, so that it will not, in fact, rise tomorrow. Ergo, the price is unpredictable. More formally, this justification relies on the law of iterated expectations and leads to a martingale. A martingale is a sequence of random variables (i.e., a stochastic process) for which, at a particular time in the realized sequence, the expectation of the next value in the sequence is equal to the present observed value even given knowledge of all prior observed values. A submartingale generalizes the martingale to cases where the expectation of the next value is greater than or equal to the present value. Bachelier (1900) and Samuelson (1965) recognised the importance of the martingale in relation to an efficient market. Whilst Cox and Ross (1976), Lucas (1978) and Harrison and Kreps (1979) pointed out that in practice investors are risk averse, so (presumably as compensation for the time value of money and systematic risk) they demand a positive expected return. In an efficient long-only market like a stock market this implies that the price of a stock follows a submartingale (a martingale being a special case when investors are risk-neutral).

Are markets becoming increasingly efficient? Although only one paper published before 1960, Cowles and Jones (1937), found significant market inefficiencies, with decreasing transaction costs, an increasing number of market participants, increasing processing power and improving algorithms, one would expect markets to become increasingly efficient. The relative proportion of the papers summarized in Sewell (2011) that reject the EMH peaked in the 1980s and 1990s, and Kim et al. (1991), Schwert (2003) and Tóth and Kertész (2006) suggest that markets are becoming increasingly efficient. It could be that markets in the 1980s and 1990s were less efficient because they were the decades of technological asymmetry: some market participants used computers, whilst others did not. It could also be that it took until the 1980s/1990s for data to be of sufficient quality and quantity to reject market efficiency with any degree of confidence. Whilst analyses post-2000 tend to support market efficiency, most likely, simply because markets have become increasingly efficient. The Red Queen effect ensures that one's ability to make money in the markets is dependent on the ability of the other market participants: the game is relative and moving.

As defined earlier, a market is said to be efficient with respect to an information set if the price 'fully reflects' that information set. On the one hand, the definitional 'fully' is an exacting requirement, suggesting that no real market could ever be efficient, implying that the EMH is almost certainly false. On the other hand, economics is a social science, and a hypothesis that is asymptotically true puts the EMH in contention for one of the strongest hypotheses in the whole of the social sciences. Strictly speaking the EMH is false, but in spirit is profoundly true. Besides, science concerns seeking the best hypothesis, and until a flawed hypothesis is replaced by a better hypothesis, criticism is of limited value.

\section{Data}

The first four pieces of work use data from the Dow Jones Industrial Average (DJIA). The Dow is the best-known US stock index, and the second-oldest (after the Dow Jones Transportation Average). The index is a price-weighted average (each constituent makes up a fraction of the index that is proportional to its price) of 30 large, publiclyowned companies based in the US. The DJIA daily closing prices from 1 October 1928 to 23 March 2012 were 
downloaded from Yahoo! Finance. The analyses were conducted independently on daily, weekly, monthly and annual log returns, as a truly efficient market should pass tests of efficiency at all time intervals. Returns, rather than price, are used as some of the statistical tests require a stationary variable. Although the Dow represents the average of its constituent stocks, care should be taken when extrapolating the characteristics of a stock index to the characteristics of individual stocks, because the existing literature (e.g. Campbell et al., 1996) reports that weekly and monthly stock returns are weakly negatively correlated, whilst daily, weekly and monthly index returns are positively correlated, the apparent paradox being due to large positive cross-autocorrelations across individual securities across time. The fifth investigation employs data from an analysis of investment newsletters, 'The Forbes/Hulbert investment letter survey' (Hulbert, 2002).

\section{Autocorrelation}

A necessary (but not sufficient) condition for the martingale hypothesis to hold is that the time series has no autocorrelation, also known as serial correlation, of any order. Note that autocorrelation is sensitive only to linear relationships.

First, consider the relevant literature on the dependence of stock market returns. Fama (1970) found that 22 out of the 30 stocks of the DJIA exhibited positive daily serial correlation. Fama and French (1988) found that autocorrelations of stock return indices (they used portfolios) form a U-shaped pattern across increasing return horizons. The autocorrelations become negative for 2-year returns, reach minimum values for 3-5-year returns, and then move back towards zero for longer return horizons. Lo and MacKinlay (1988) found significant positive serial correlation for weekly and monthly holding-period index returns, but negative autocorrelations for individual securities with weekly data. Ball and Kothari (1989) found negative serial correlation in five-year stock returns. Lo and MacKinlay (1990) found negative autocorrelation in the weekly returns of individual stocks, whilst weekly portfolio returns were strongly positively autocorrelated. Jegadeesh (1990) found highly significant negative serial correlation in monthly individual stock returns and strong positive serial correlation at twelve months. Brock et al. (1992) found positive autocorrelation in DJIA daily returns. Boudoukh et al. (1994) found that for smallfirm indices, the spot index's autocorrelation is significantly higher than that of the futures. Longin (1996) found positive autocorrelation for a daily index of stocks. As noted earlier, Campbell et al. (1996) reported that the autocorrelation of weekly stock returns is weakly negative, whilst the autocorrelations of daily, weekly and monthly stock index returns are positive. Lo and MacKinlay (1999) found a positive autocorrelation for weekly holdingperiod market indices returns, but a random walk for monthly. They also found negative serial correlation for individual stocks with weekly data. Cont (2001) found negative autocorrelation on a tick-by-tick basis for a stock (KLM shares traded on the New York Stock Exchange (NYSE)). He also claims that weekly and monthly autocorrelations exist. Ahn et al. (2002) found that the daily autocorrelations of stock indices are nearly all positive (whilst the daily autocorrelations of the corresponding futures contracts are close to zero). Lewellen (2002) found negative autocorrelation for stock portfolios after a year. Llorente et al. (2002) found that the firstorder autocorrelation of daily returns is negative for stocks with large bid-ask spreads (-0.088) and small sizes $(-0.076)$, but positive but very small for large stocks $(0.003)$ and stocks with small bid-ask spreads $(0.01)$. Bianco and Renò (2006) found negative serial correlation in the returns of Italian stock index futures for periods smaller than 20 minutes. Lim et al. (2008) examined ten Asian emerging stock markets and discovered that all the returns series exhibit non-linear serial dependence. Serletis and Rosenberg (2009) analysed daily data on four US stock market indices and concluded that US stock market returns display mean reversion.

Table 1. First-order autocorrelation of DJIA log returns

\begin{tabular}{cc}
\hline Time interval & Autocorrelation \\
\hline Daily & 0.0138 \\
Weekly & 0.0117 \\
Monthly & 0.0793 \\
Annual & 0.1194 \\
\hline
\end{tabular}

In the current paper, the first-order autocorrelation of daily, weekly, monthly and annual DJIA log returns was measured. Note that due to the definition of autocorrelation, detrending the data is not necessary (the results will be the same). Table 1 shows the autocorrelation of DJIA returns. Autocorrelation is small but positive for all time periods. The autocorrelations for daily and weekly returns are the closest to zero, and thus (potentially) an efficient market. 


\section{Runs Test}

The third and fourth analyses concern applications of the runs test, a non-parametric statistical test that can be used to test for serial dependence, a lack of dependence being a necessary (but not sufficient) condition for the martingale hypothesis to hold. In contrast to autocorrelation, the runs test loses information because the magnitude of the returns is lost. However, whilst autocorrelation can detect only linear relationships, the runs test can detect both linear and non-linear relationships. The runs test assumes that the sequence is not only uncorrelated, but also serially independent and identically distributed. If a sequence has zero mean, the runs test becomes a direct test of a martingale.

A 'run' within a sequence is a maximal non-empty consecutive subsequence consisting of adjacent equal elements. For example, the sequence ' +---+-++++-+ ' consists of seven runs. Given a sequence of length $n$ with $n_{+}$occurrences of ' + ' and $n_{-}$occurrences of '- ' (so $n=n_{+}+n_{-}$), if each element in the sequence is independent, then the number of runs is a random variable with an approximately normal distribution, mean $\mu$ and variance $\sigma^{2}$, where

and

$$
\mu=\frac{2 n_{+} n_{-}}{n}+1
$$

$$
\sigma^{2}=\frac{2 n_{+} n_{-}\left(2 n_{+} n_{-}-n\right)}{n^{2}(n-1)}=\frac{(\mu-1)(\mu-2)}{n-1} .
$$

Table 2. The actual and expected total number of runs, where a run is a consecutive sequence of DJIA log returns above (below) the mean return. ${ }^{*}$ indicates statistical significance at the $10 \%$ level, ${ }^{* *} 5 \%,{ }^{* * *} 1 \%,{ }^{* * * *} 0.5 \%$ and ***** $0.1 \%$

\begin{tabular}{lccccl}
\hline Time interval & Actual number & Expected number & Standard deviation & $z$-score & $p$-value \\
\hline Daily & 10064 & 10476.4512 & 72.3478 & -5.7010 & $0.0000^{* * * * *}$ \\
Weekly & 2140 & 2164.6095 & 32.7894 & -0.7505 & 0.2265 \\
Monthly & 487 & 496.7680 & 15.6696 & -0.6234 & 0.2665 \\
Annual & 42 & 41.7711 & 4.4469 & 0.0515 & 0.4795 \\
\hline
\end{tabular}

If the number of runs is significantly higher or lower than expected, the hypothesis of statistical independence may be rejected. Consider the DJIA closing prices. There is no need to detrend the data. A run is a consecutive sequence of returns above (below) the mean return. The above runs test is performed on daily, weekly, monthly and annual returns, in chronological order. The statistics generated by the runs test are displayed in Table 2, and show the actual and expected total number of runs. The statistics clearly show that the null hypothesis of independence is strongly rejected for daily returns, but accepted for weekly, monthly and annual returns. The results show that daily returns are the least consistent with an efficient market, whilst annual returns approximate an efficient market. Fama (1965) performed a similar runs test on the price changes of stocks, but only considered the expected number of runs, so no statistical tests were performed.

However, we can go further, and consider the number of increasing runs, and the number of decreasing runs, for runs of length $i$, and compare this with a random walk. Let $Y_{i}$ be the number of increasing (decreasing) runs of length $i$ in a sequence of $n$ numbers. Then the expected value for $Y_{i}$ runs is given by

$$
E\left(Y_{i}\right)=\frac{2}{(i+3) !}\left[n\left(i^{2}+3 i+1\right)-\left(i^{3}+3 i^{2}-i-4\right)\right] \text { for } i \leq n-2
$$

and

$$
E\left(Y_{i}\right)=\frac{2}{n !} \text { for } i=n-1 .
$$

The algorithm for the standard deviation of the number of runs is available via the Visual Basic code written within the Excel spreadsheet available online at http://www.stats.org.uk/runs-test.xls. If the number of runs of a particular length is significantly higher or lower than expected, the hypothesis of statistical independence may be rejected. 
Table 3. DJIA daily returns: increasing. In Tables 3-10, an increasing run refers to a sequence of increasing returns such as $-0.2,-0.1,0,0.1,0.2$, whilst a decreasing run refers to a sequence of decreasing returns such as $0.2,0.1,0$, $-0.1,-0.2$. $^{*}$ indicates statistical significance at the $10 \%$ level, ${ }^{* *} 5 \%,{ }^{* *} 1 \%,{ }^{* * *} 0.5 \%$ and ${ }^{* * * *} 0.1 \%$

\begin{tabular}{ccccrl}
\hline Length of run & Number of runs & Expectation & Standard deviation & $z$-score & $p$-value \\
\hline 1 & 3947 & 4367.5417 & 66.6337 & -6.3112 & $0.0000^{* * * * *}$ \\
2 & 1995 & 1921.5833 & 34.3642 & 2.1364 & $0.0163^{* *}$ \\
3 & 556 & 553.1514 & 20.9601 & 0.1359 & 0.4459 \\
4 & 122 & 120.6056 & 10.6237 & 0.1313 & 0.4478 \\
5 & 15 & 21.3128 & 4.5827 & -1.3775 & $0.0842^{*}$ \\
6 & 4 & 3.1765 & 1.7799 & 0.4626 & 0.3218 \\
7 & 0 & 0.4100 & 0.6402 & -0.6405 & 0.2609 \\
8 & 0 & 0.0467 & 0.2162 & -0.2162 & 0.4144 \\
9 & 0 & 0.0048 & 0.0691 & -0.0691 & 0.4725 \\
10 & 0 & 0.0004 & 0.0210 & -0.0210 & 0.4916 \\
\hline
\end{tabular}

Table 4. DJIA daily returns: decreasing

\begin{tabular}{ccccrl}
\hline Length of run & Number of runs & Expectation & Standard deviation & $z$-score & $p$-value \\
\hline 1 & 3701 & 4367.5417 & 66.6337 & -10.0031 & $0.0000^{* * * * *}$ \\
2 & 2027 & 1921.5833 & 34.3642 & 3.0676 & $0.0011^{* * * *}$ \\
3 & 673 & 553.1514 & 20.9601 & 5.7180 & $0.0000^{* * * * *}$ \\
4 & 193 & 120.6056 & 10.6237 & 6.8144 & $0.0000^{* * * * *}$ \\
5 & 40 & 21.3128 & 4.5827 & 4.0778 & $0.0000^{* * * * *}$ \\
6 & 3 & 3.1765 & 1.7799 & -0.0992 & 0.4605 \\
7 & 1 & 0.4100 & 0.6402 & 0.9215 & 0.1784 \\
8 & 0 & 0.0467 & 0.2162 & -0.2162 & 0.4144 \\
9 & 0 & 0.0048 & 0.0691 & -0.0691 & 0.4725 \\
10 & 0 & 0.0004 & 0.0210 & -0.0210 & 0.4916 \\
\hline
\end{tabular}

Table 5. DJIA weekly returns: increasing

\begin{tabular}{ccccrl}
\hline Length of run & Number of runs & Expectation & Standard deviation & $z$-score & $p$-value \\
\hline 1 & 958 & 906.9167 & 30.3603 & 1.6826 & $0.0462^{* *}$ \\
2 & 373 & 398.9083 & 15.6569 & -1.6548 & $0.0490^{* *}$ \\
3 & 99 & 114.8056 & 9.5490 & -1.6552 & $0.0489^{* *}$ \\
4 & 25 & 25.0264 & 4.8394 & -0.0055 & 0.4978 \\
5 & 0 & 4.4217 & 2.0873 & -2.1183 & $0.0171^{* *}$ \\
6 & 0 & 0.6589 & 0.8106 & -0.8128 & 0.2082 \\
7 & 0 & 0.0850 & 0.2916 & -0.2917 & 0.3853 \\
8 & 0 & 0.0097 & 0.0984 & -0.0984 & 0.4608 \\
9 & 0 & 0.0010 & 0.0314 & -0.0314 & 0.4875 \\
10 & 0 & 0.0001 & 0.0096 & -0.0096 & 0.4962 \\
\hline
\end{tabular}

Table 6. DJIA weekly returns: decreasing

\begin{tabular}{ccccrl}
\hline Length of run & Number of runs & Expectation & Standard deviation & $z$-score & $p$-value \\
\hline 1 & 891 & 906.9167 & 30.3603 & -0.5243 & 0.3000 \\
2 & 387 & 398.9083 & 15.6569 & -0.7606 & 0.2235 \\
3 & 131 & 114.8056 & 9.5490 & 1.6959 & $0.0450^{\text {** }}$ \\
4 & 38 & 25.0264 & 4.8394 & 2.6808 & $0.0037^{\text {**** }}$ \\
5 & 7 & 4.4217 & 2.0873 & 1.2352 & 0.1084 \\
6 & 1 & 0.6589 & 0.8106 & 0.4208 & 0.3370 \\
7 & 0 & 0.0850 & 0.2916 & -0.2917 & 0.3853 \\
8 & 0 & 0.0097 & 0.0984 & -0.0984 & 0.4608 \\
9 & 0 & 0.0010 & 0.0314 & -0.0314 & 0.4875 \\
10 & 0 & 0.0001 & 0.0096 & -0.0096 & 0.4962 \\
\hline
\end{tabular}


Table 7. DJIA monthly returns: increasing

\begin{tabular}{ccccrc}
\hline Length of run & Number of runs & Expectation & Standard deviation & $z$-score & $p$-value \\
\hline 1 & 224 & 208.3750 & 14.5453 & 1.0742 & 0.1414 \\
2 & 84 & 91.5500 & 7.5002 & -1.0066 & 0.1571 \\
3 & 25 & 26.3236 & 4.5727 & -0.2895 & 0.3861 \\
4 & 4 & 5.7333 & 2.3164 & -0.7483 & 0.2271 \\
5 & 1 & 1.0121 & 0.9987 & -0.0121 & 0.4952 \\
6 & 0 & 0.1507 & 0.3877 & -0.3887 & 0.3487 \\
7 & 0 & 0.0194 & 0.1394 & -0.1394 & 0.4446 \\
8 & 0 & 0.0022 & 0.0470 & -0.0470 & 0.4812 \\
9 & 0 & 0.0002 & 0.0150 & -0.0150 & 0.4940 \\
10 & 0 & 0.0000 & 0.0046 & -0.0046 & 0.4982 \\
\hline
\end{tabular}

Table 8. DJIA monthly returns: decreasing

\begin{tabular}{ccccrl}
\hline Length of run & Number of runs & Expectation & Standard deviation & $z$-score & $p$-value \\
\hline 1 & 200 & 208.3750 & 14.5453 & -0.5758 & 0.2824 \\
2 & 110 & 91.5500 & 7.5002 & 2.4599 & $0.0069^{* * *}$ \\
3 & 25 & 26.3236 & 4.5727 & -0.2895 & 0.3861 \\
4 & 4 & 5.7333 & 2.3164 & -0.7483 & 0.2271 \\
5 & 0 & 1.0121 & 0.9987 & -1.0135 & 0.1554 \\
6 & 0 & 0.1507 & 0.3877 & -0.3887 & 0.3487 \\
7 & 0 & 0.0194 & 0.1394 & -0.1394 & 0.4446 \\
8 & 0 & 0.0022 & 0.0470 & -0.0470 & 0.4812 \\
9 & 0 & 0.0002 & 0.0150 & -0.0150 & 0.4940 \\
10 & 0 & 0.0000 & 0.0046 & -0.0046 & 0.4982 \\
\hline
\end{tabular}

Table 9. DJIA annual returns: increasing

\begin{tabular}{ccccrc}
\hline Length of run & Number of runs & Expectation & Standard deviation & $z$-score & $p$-value \\
\hline 1 & 18 & 17.3333 & 4.1640 & 0.1601 & 0.4364 \\
2 & 5 & 7.4917 & 2.1434 & -1.1625 & 0.1225 \\
3 & 2 & 2.1250 & 1.3004 & -0.0961 & 0.4617 \\
4 & 0 & 0.4569 & 0.6542 & -0.6984 & 0.2425 \\
5 & 0 & 0.0797 & 0.2802 & -0.2843 & 0.3881 \\
6 & 0 & 0.0117 & 0.1081 & -0.1084 & 0.4568 \\
7 & 0 & 0.0015 & 0.0386 & -0.0386 & 0.4846 \\
8 & 0 & 0.0002 & 0.0130 & -0.0130 & 0.4948 \\
9 & 0 & 0.0000 & 0.0041 & -0.0041 & 0.4984 \\
10 & 0 & 0.0000 & 0.0012 & -0.0012 & 0.4995 \\
\hline
\end{tabular}

Table 10. DJIA annual returns: decreasing

\begin{tabular}{ccccrl}
\hline Length of run & Number of runs & Expectation & Standard deviation & $z$-score & $p$-value \\
\hline 1 & 10 & 17.3333 & 4.1640 & -1.7611 & $0.0391^{* *}$ \\
2 & 10 & 7.4917 & 2.1434 & 1.1702 & 0.1210 \\
3 & 6 & 2.1250 & 1.3004 & 2.9798 & $0.0014^{* * * *}$ \\
4 & 0 & 0.4569 & 0.6542 & -0.6984 & 0.2425 \\
5 & 0 & 0.0797 & 0.2802 & -0.2843 & 0.3881 \\
6 & 0 & 0.0117 & 0.1081 & -0.1084 & 0.4568 \\
7 & 0 & 0.0015 & 0.0386 & -0.0386 & 0.4846 \\
8 & 0 & 0.0002 & 0.0130 & -0.0130 & 0.4948 \\
9 & 0 & 0.0000 & 0.0041 & -0.0041 & 0.4984 \\
10 & 0 & 0.0000 & 0.0012 & -0.0012 & 0.4995 \\
\hline
\end{tabular}

Again, the above runs test is performed on daily, weekly, monthly and annual DJIA returns, in chronological order. Here, in contrast to the first runs test, 'runs up' refers to a sequence of increasing returns such as $-0.2,-0.1,0,0.1$, 
0.2 , whilst 'runs down' refers to a sequence of decreasing returns such as $0.2,0.1,0,-0.1,-0.2$. Again, there is no need to detrend the data. Note that in neither of the two tests is it necessary to assume that the '+'s and '-'s have equal probabilities, the tests only assume that the elements are independent and identically distributed. The results of this runs test are given in Tables 3-10. The tables show, for each run length, the actual and expected number of increasing (decreasing) runs, the $z$-score, the $p$-value and the degree of any statistical significance. When compared to a random walk, returns are significantly less likely to increase or decrease for just one day, and far more likely to deteriorate for 2-5 days in a row. Returns are more likely to increase for just one week, or deteriorate for three or more weeks, relative to a random walk. The returns deteriorated for two successive months more frequently than expected. The market returns deteriorated for three successive years more frequently than would be expected from a random walk, and were relatively unlikely to decrease for just one year. The only run of increasing annual returns that was over-represented was of length one. The results for annual returns are consistent with a business cycle. Overall, the results show that daily, weekly and decreasing returns are the least consistent with an efficient market, most likely due to the presence of non-linearities.

\section{Long Memory}

If a time series exhibits long memory, then even the distant past continues to influence the future. Given the efficient market hypothesis, for a stock market to exhibit long memory would be a surprising result. Clearly then, another necessary (but not sufficient) condition for the martingale hypothesis to hold is that the time series has no long memory. A random process has long memory when its autocorrelation function has hyperbolic decay.

First, consider the existing literature, which began when Mandelbrot (1972) applied $R / S$ analysis to financial returns. Greene and Fielitz (1977) claimed that many daily stock return series are characterized by long-term dependence. Aydogan and Booth (1988) concluded that there was no significant evidence for long-term memory in common stock returns. Lo (1991) modified the $R / S$ statistic to ensure that it is robust to short-range dependence and found little evidence of long-term memory in historical US stock market returns. Goetzmann (1993) considered three centuries of stock market prices. $R / S$ tests provided some evidence that detrended London Stock Exchange and NYSE prices may exhibit long-term memory. Mills (1993) found little evidence of long memory in daily UK stock returns. Nawrocki (1995) considered the CRSP monthly value-weighted index and the S\&P 500 daily index, and found that the Hurst exponent and the Lo-modified $R / S$ statistic indicate that there is persistent finite memory. Chow et al. (1996) found evidence that consistently revealed the absence of long-term dependence in 22 international equity market indices. Lux (1996) analysed German stock market data and found no evidence for long-term dependence in the returns series. Barkoulas and Baum (1996) applied the spectral regression method and found no evidence of long memory in either aggregate or sectoral stock indices, but evidence of long memory in 5, intermediate memory in 3 and no fractal structure in 22 of the 30 DJIA companies. Their overall findings did not offer convincing evidence against the martingale model. Hiemstra and Jones (1997) applied the modified rescaled range test to the return series of 1,952 common stocks and their results indicated that long memory is not a widespread characteristic of those stocks. Lobato and Savin (1998) found no evidence of long memory in daily stock returns. Willinger et al. (1999) found empirical evidence of long-range dependence in stock price returns, but the evidence was not absolutely conclusive. Huang and Yang (1999) applied the modified $R / S$ technique to intraday data and found long-term memory in both NYSE and NASDAQ indices. Using the spectral regression method, Barkoulas et al. (2000) found significant and robust evidence of long-term persistence in the Greek stock market. Chen (2000) calculated Hurst's classical rescaled range statistic for seven Asia-Pacific countries' stock indices and concluded that all the index returns have long memory. Zhuang et al. (2000) investigated British stock returns and found little or no evidence of long-range dependence. Sadique and Silvapulle (2001) examined the presence of long memory in the weekly stock returns of seven countries, namely Japan, Korea, New Zealand, Malaysia, Singapore, the US and Australia. They found evidence for long-term dependence in four countries: Korea, Malaysia, Singapore and New Zealand. Nath (2001) found indications of long-term memory in the Indian stock market using $R / S$ analysis, but suggested that a more rigid analysis, such as Lo's modified $R / S$ statistic, should be used. Panas (2001) found long memory in the Athens Stock Exchange. Cavalcante and Assaf (2002) found little evidence of long memory in the returns of the Brazilian stock market. Henry (2002) investigated long-range dependence in nine international stock index returns. He found evidence of long memory in four of them, the German, Japanese, South Korean and Taiwanese markets, but not for the markets of the UK, US, Hong Kong, Singapore and Australia. Tolvi (2003b) found long memory in Finnish stock market return data. Using a monthly data set consisting of stock market indices of 16 OECD countries, Tolvi (2003a) found statistically significant long memory for three countries: Denmark, Finland and Ireland, which are all small markets. Limam (2003) analysed stock index returns in 14 markets and concluded that long memory tends to be associated with 
thin markets. Cajueiro and Tabak (2004) found that the markets of Hong Kong, Singapore and China exhibit longrange dependence. Naively, Cajueiro and Tabak (2005) state that 'the presence of long-range dependence in asset returns seems to be a stylized fact'. They studied the individual stocks in the Brazilian stock market and found evidence that firm-specific variables can explain, at least partially, the long-range dependence phenomena. GrauCarles (2005) applied four tests for long memory to two major daily stock indices, the S\&P 500 and the DJIA, two samples from each. There was no evidence of long memory in the returns. Oh et al. (2006) studied long-term memory in various stock market indices (using both one-minute and daily data) by applying detrended fluctuation analysis. No significant long-term memory was detected in any of the return series. Elder and Serletis (2007) found no evidence of long memory in the DJIA. Oh et al. (2008) studied long-term memory in two Korean stock market indices using detrended fluctuation analysis. No significant long-term memory was detected in either of the return series. Serletis and Rosenberg (2009) used daily data on four US stock market indices and concluded that US stock market returns display anti-persistence. Tan et al. (2010) found evidence of long memory in the Malaysian stock market before the 1997 financial crisis, but not afterwards. Kang et al. (2010) tested the daily closing prices of the KOSPI 50 index and its 50 constituent stock prices for long memory. Their broad conclusion was that there is no long memory in the return series of the Korean stock market. Rege and Martín (2011) calculated the Hurst exponent for the Portuguese stock market and concluded that it exhibits both long memory and short memory depending on the scale of the time period used. Mishra et al. (2011) used R/S analysis on daily returns from the Indian stock market to reveal strong evidence of persistence or temporal dependencies. Mukherjee et al. (2011) found no evidence for long memory in the Indian stock market. Anoruo and Gil-Alana (2011) examined the daily closing prices of CASE 30 (Egypt), MASI (Morocco), TUNINDEX (Tunisia) and NSE All Share (Nigeria), and monthly data from SEM (Mauritius), NSE 20 (Kenya), JSE All Share (South Africa), ZSE Industrials (Zimbabwe), BSE (Botswana) and JSE All Share (Namibia), and found evidence of long memory in the returns in the cases of Egypt and Nigeria, and, to a lesser extent, for Tunisia, Morocco and Kenya. Boubaker and Makram (2012) found strong evidence of long memory in North African stock market returns. In summary, about half of the articles concluded that stock market returns exhibit long memory, with the rest finding no evidence.

Let us formally define long memory. Following Beran (1994, p. 42), if $\rho(k)$ is the correlation at lag $k$, let $X_{t}$ be a stationary process for which the following holds. There exists a real number $\alpha \in(0,1)$ and a constant $c_{p}>0$ such that

$$
\lim _{k \rightarrow \infty} \frac{\rho(k)}{c_{\rho} k^{-\alpha}}=1 .
$$

Then $X_{t}$ is called a stationary process with long memory or long-range dependence or strong dependence, or a stationary process with slowly decaying or long-range correlations.

The parameter $H=1-\frac{\alpha}{2}$ is normally used instead of $\alpha$. In terms of this parameter, long memory occurs for $\frac{1}{2}<H<1$. Knowing the covariances (or correlations and variance) is equivalent to knowing the spectral density $f$. Therefore, long-range dependence can also be defined by imposing a condition on the spectral density. If $f(\lambda)$ is the spectral density, let $X_{t}$ be a stationary process for which the following holds: there exists a real number $\beta \in(0,1)$ and a constant $c_{f}>0$ such that

$$
\lim _{\lambda \rightarrow 0} \frac{f(\lambda)}{c_{f}|\lambda|^{-\beta}}=1 .
$$

Then $X_{t}$ is called a stationary process with long memory or long-range dependence or strong dependence.

In 1906, Harold Edwin Hurst, a young English civil servant, came to Cairo, Egypt, which was then under British rule. As a hydrological consultant, Hurst's problem was to predict how much the Nile flooded from year to year. He developed a test for long-range dependence and found significant long-term correlations among fluctuations in the Nile's outflows and described these correlations in terms of power laws. This statistic is known as the rescaled range, range over standard deviation or $R / S$ statistic. From 1951 to 1956, Hurst, then in his seventies, published a series of papers describing his findings (Hurst, 1951).

Hurst's rescaled range $(R / S)$ statistic is the range of partial sums of deviations of a time series from its mean, rescaled by its standard deviation. If $\left\{r_{1}, r_{2}, \ldots, r_{n}\right\}$ is a sample of continuously compounded asset returns and $\bar{r}_{n}$ the sample mean $\frac{1}{n} \sum_{j} r_{j}$, then the rescaled-range statistic, $R / S$, is given by

$$
R / S \equiv \frac{1}{s_{n}}\left[\max _{1 \leq k \leq n} \sum_{j=1}^{k}\left(r_{j}-\bar{r}_{n}\right)-\min _{1 \leq k \leq n} \sum_{j=1}^{k}\left(r_{j}-\bar{r}_{n}\right)\right]
$$


where $s_{n}$ is the standard deviation,

$$
s_{n} \equiv\left[\frac{1}{n} \sum_{j}\left(r_{j}-\bar{r}_{n}\right)^{2}\right]^{1 / 2} .
$$

The Hurst exponent, $H$, is defined by

$$
R / S=c n^{H}
$$

(where $c$ is a constant) and estimated using the following regression

$$
\log R / S=\log c+H \log n .
$$

Intuitively, the first term within the square brackets in (1) will be large and positive if there are many large successive positive returns, and the second term will be large and negative if there are many large successive negative returns, so $R / S$, and hence $H$, will be large if the returns show persistence. Further, (1) utilizes the sum of deviations from the mean over a sequence of returns, rather than merely comparing successive returns, so measures long-term persistence.

Two implementations of software for measuring Hurst's rescaled range $(R / S)$ statistic were written, one in Visual Basic for Excel, and one in C++. Both are available online at http://www.long-memory.com. In both cases, the input sequence should be stationary, with mean zero. So if analysing financial data, the input data must be 1) returns (not price) and 2) detrended (zero mean). It should be noted that a given time series has a single value of $H$, but measurements taken at different timescales will produce different approximations of $H$. The spreadsheet version also generates a graph of $\log (R / S)$ against $\log ($ time $)$ and one can also identify cycles in the time series from kinks in the line.

The $\mathrm{C}++$ program was run on daily, weekly, monthly and annual detrended DJIA returns. In order to make the processing time reasonable, a maximum of 1000 data points were processed at a time. The daily data was processed in 21 batches and the weekly data was processed in 5 batches. In both cases the mean value of $H$ was calculated.

Table 11. Rescaled range analysis on detrended DJIA log returns

\begin{tabular}{cc}
\hline Time interval & $H$ \\
\hline Daily & 0.5645 \\
Weekly & 0.5802 \\
Monthly & 0.5571 \\
Annual & 0.6004 \\
\hline
\end{tabular}

My implementation of $R / S$ analysis calculates $H$ as accurately as possible, although suffers from long run times (even the $\mathrm{C}++$ version took one hour twenty minutes to process 1000 data points on a PC with a $1.66 \mathrm{GHz}$ Intel Core Duo Processor T2300 and 2GB of RAM). Table 11 shows the results of the analysis on detrended DJIA returns, which appear to show persistence. However, in light of the fact that $R / S$ analysis fails to distinguish between short-range dependence and long-range dependence (Lo, 1991), and the fact that DJIA returns showed positive autocorrelation (Section 4), I cannot conclude that there is significant evidence for the existence of long memory in stock returns, so the results are consistent with an efficient market.

\section{Investment Newsletters}

The fifth and final piece of work concerns an analysis of investment newsletters, and a literature review follows.

Graham and Harvey (1996) analysed the advice contained in a sample of 237 investment newsletter strategies over the period 1980-1992 and found that there is little information in the investment newsletters' opinions regarding stock market direction. However they did find that the degree of disagreement among newsletters predicts both realized and expected volatility as well as trading volume. Graham and Harvey (1997) examined the performance of 326 newsletter asset-allocation strategies for the period 1983-1995. They found that, as a group, newsletters do not appear to possess any special information about the future direction of the market. Nevertheless, they found that investment newsletters that are on a hot streak (have correctly anticipated the direction of the market in previous recommendations) may provide valuable information about future returns. The Value Line Investment Survey is the best known investment newsletter, it is well-respected and freely available. Graham (1999) found that a newsletter analyst is likely to herd on Value Line's recommendation if his reputation is high, if his ability is 
low or if the correlation across analysts' signals is high. Jaffe and Mahoney (1999) analysed the recommendations of common stocks made by the investment newsletters followed by the Hulbert Financial Digest. Taken as a whole, the securities that newsletters recommend did not outperform appropriate benchmarks and the performance of the newsletters did not exhibit persistence. They found little, if any, evidence of herding. Newsletters tend to recommend securities that have performed well in the recent past and newsletters with poor past performance are more likely to go out of business. Metrick (1999) analysed the equity-portfolio recommendations made by 153 investment newsletters. Overall, there was no significant evidence of superior stock-picking ability and no evidence of abnormal short-run performance persistence ('hot hands'). Kumar and Pons (2002) analysed the behaviour and performance of 353 investment newsletters that made asset allocation recommendations during a period covering more than 21 years (June 1980-November 2001). On aggregate the newsletters failed to outperform a passive investment strategy, but active newsletters and contrarian newsletters exhibited market-timing ability. When they examined the recommendations of individual newsletters at a higher frequency (daily as opposed to monthly), they found considerable evidence of timing ability. There was also evidence of persistence in newsletters' performance and a trading strategy that followed the average recommendations of newsletters that have performed well in the past 10 months is capable of outperforming the market on a risk-adjusted basis (the annual over-performance is 2.56 per cent).

Before describing the method employed here, three definitions are in order. Fundamental analysis is a method of forecasting markets through the analysis of relevant news, whilst technical analysis is a method of forecasting markets through the analysis of data generated from the activity of trading itself. The Sharpe ratio is the most popular investment performance metric. Where $R$ is the asset return, $R_{f}$ is the return on a benchmark asset, such as the risk free rate of return, $E\left[R-R_{f}\right]$ is the expected value of the excess of the asset return over the benchmark return, and $\sigma=\sqrt{\operatorname{Var}\left[R-R_{f}\right]}$ is the standard deviation of the excess return,

$$
\text { Sharpe ratio }=\frac{E\left[R-R_{f}\right]}{\sigma} .
$$

If a market is weak form efficient, then technical analysis has no value, whilst if a market is semi-strong form efficient, then technical analysis has no value and fundamental analysis has no value.

Table 12. 'Up markets' and 'down markets' as defined by Hulbert (2002)

\begin{tabular}{lll}
\hline Start & End & Market \\
\hline 31 May 1990 & 31 October 1990 & down \\
1 November 1990 & 29 June 1990 & up \\
30 June 1998 & 31 August 1998 & down \\
1 September 1998 & 29 June 1999 & up \\
30 June 1999 & 30 September 1999 & down \\
1 October 1999 & 30 March 2000 & up \\
31 March 2000 & 31 December 2001 & down \\
\hline
\end{tabular}

'The Forbes/Hulbert investment letter survey' (Hulbert, 2002) was purchased. The data encompasses performance from 31 May 1990 to 31 December 2001 and includes just those newsletters tracked by The Hulbert Financial Digest that have a predominant US equity focus. The editors of the listed newsletters were contacted in order to determine whether each newsletter was based on technical analysis, fundamental analysis or a combination of the two (in which case they were asked to what degree each type of analysis was used). Hulbert (2002) split the nearly dozen-year span into 'up market' (bull) and 'down market' (bear) periods, as shown in Table 12. The data was analysed by performing correlation analysis on the quantitative data. The raw data is proprietary, so is omitted.

The results of the analysis of investment newsletters are given in Table 13. The results showed a strongly negative correlation between returns in a bull market and returns in a bear market and a strongly negative correlation between risk (standard deviation) and returns in a bear market. Also, technical analysts underperformed the market, and their results were particularly poor during bull markets. Of eight purely fundamental newsletters, two beat the market, of nine purely technical newsletters, none beat the market. In particular, the risk-adjusted performance of the technical newsletters was derisory. If we assume that the market had a Sharpe ratio of $100 \%$, the average purely technical newsletter had a Sharpe ratio of $24 \%$. It can be concluded that technical analysis-as applied by practitioners-fails to outperform the market, which is consistent with weak form efficiency. 
Table 13. Correlation analysis of 'The Forbes/Hulbert investment letter survey'. Bull return refers to the newsletter returns in 'up markets' and bear return refers to the newsletter returns in 'down markets', as defined in Table 12. Price refers to the price of the newsletter. The standard deviation (SD) of returns is a proxy for risk

\begin{tabular}{lcccccccc}
\hline & Bull ret. & Bear ret. & Price & SD & Return & Sharpe & \% Fund. & $\%$ Tech. \\
\hline Bull return & 1.00 & -0.71 & 0.16 & 0.53 & 0.53 & 0.53 & 0.51 & -0.51 \\
Bear return & -0.71 & 1.00 & -0.09 & -0.71 & -0.21 & -0.03 & -0.12 & 0.12 \\
Price & 0.16 & -0.09 & 1.00 & 0.28 & -0.16 & -0.03 & 0.40 & -0.40 \\
Standard deviation & 0.53 & -0.71 & 0.28 & 1.00 & -0.19 & -0.24 & 0.13 & -0.13 \\
Return & 0.53 & -0.21 & -0.16 & -0.19 & 1.00 & 0.84 & 0.42 & -0.42 \\
Sharpe ratio & 0.53 & -0.03 & -0.03 & -0.24 & 0.84 & 1.00 & 0.53 & -0.53 \\
\% Fundamental analysis & 0.51 & -0.12 & 0.40 & 0.13 & 0.42 & 0.53 & 1.00 & -1.00 \\
\% Technical analysis & -0.51 & 0.12 & -0.40 & -0.13 & -0.42 & -0.53 & -1.00 & 1.00 \\
\hline
\end{tabular}

\section{Conclusion}

Table 14. Summary. The extent to which the four statistical tests rejected market efficiency across different time periods

\begin{tabular}{lllll}
\hline & Daily & Weekly & Monthly & Annual \\
\hline Autocorrelation & & & inefficient & inefficient \\
Runs test 1 & inefficient & & & \\
Runs test 2 & inefficient & inefficient & & \\
Long memory & & & & \\
\hline
\end{tabular}

The investigation into autocorrelation found that detrended DJIA log returns exhibit persistence, when measured at daily, weekly, monthly and (especially) annual intervals. The runs test uncovered highly significant patterns in DJIA daily returns that are inconsistent with an efficient market. For example, a run of just one decreasing return is relatively unusual. This means that if returns improve on day one, then deteriorate the following day, they are more likely to deteriorate on the third day, than improve. Considering annual returns, relative to a random walk, the most common run of improved returns is one, and the most common run of deteriorating returns is three, totalling four years, which is consistent with a business cycle. Table 14 summarises the extent to which the first four analyses rejected market efficiency across different time periods.

The tests of autocorrelation and long memory show annual returns to be the least consistent with a martingale, which makes sense, as markets may be less efficient in the longer term because in practice investors have finite time horizons. In contrast, the runs tests showed the daily returns to be the least consistent with a martingale. Autocorrelation only detects linear relationships, not non-linear relationships, whilst the runs test has no such restriction. There is ample empirical evidence that a non-linear process contributes to the dynamics of market returns (Hsieh, 1989; Scheinkman \& LeBaron, 1989; Brock et al., 1991). This gives support for the efficacy of technical analysis, which relies on non-linearities being present (Neftci, 1991). In their review paper, Park and Irwin (2004) found that, on average, non-linear methods outperformed genetic programming in all three types of market considered: stock markets, futures markets and currency markets. So are stock markets efficient or not? In sum, this paper reconciles the apparent efficiency of markets according to linear statistical tests with the potential for non-linear forecasting methods to generate above-average risk-adjusted returns. Whilst the results of the investment newsletter analysis implied that technical analysis, as applied by the newsletter writers, holds no value. This is not surprising, as most such practitioners take a naive discretionary approach to technical analysis.

\section{Acknowledgements}

The author would like to thank David Barber, Edward Tsang and two anonymous reviewers for helpful comments.

\section{References}

Ahn, D.-H., Boudoukh, J., Richardson, M., \& Whitelaw, R. F. (2002). Partial adjustment or stale prices? Implications from stock index and futures return autocorrelations. The Review of Financial Studies, 15(2), 655-689. http://dx.doi.org/10.1093/rfs/15.2.655

Anoruo, E., \& Gil-Alana, L. A. (2011). Mean reversion and long memory in African stock market prices. Journal of Economics and Finance, 35(3), 296-308. http://dx.doi.org/10.1007/s12197-010-9124-0 
Aydogan, K., \& Booth, G. G. (1988). Are there long cycles in common stock returns? Southern Economic Journal, 55(1), 141-149. http://dx.doi.org/10.2307/1058862

Bachelier, L. (1900). Theéorie de la spéculation. Annales Scientifiques de l'École Normale Supérieure Sér., 3(17), 21-86.

Ball, R., \& Kothari, S. P. (1989). Nonstationary expected returns: Implications for tests of market efficiency and serial correlation in returns. Journal of Financial Economics, 25(1), 51-74. http://dx.doi.org/10.1016/0304-405X(89)90096-2

Barkoulas, J. T., \& Baum, C. F. (1996). Long-term dependence in stock returns. Economics Letters, 53(3), 253259.

Barkoulas, J. T., Baum, C. F., \& Travlos, N. (2000). Long memory in the Greek stock market. Applied Financial Economics, 10(2), 177-184.

Beja, A. (1977). The limits of price information in market processes. Working paper 61, University of California, Berkeley, Berkeley. Research Program in Finance.

Beran, J. (1994). Statistics for Long-Memory Processes, volume 61 of Monographs on Statistics and Applied Probability. Chapman \& Hall/CRC, Boca Raton.

Bianco, S., \& Renò, R. (2006). Dynamics of intraday serial correlation in the Italian futures market. The Journal of Futures Markets, 26(1), 61-84. http://dx.doi.org/10.1002/fut.20182

Boubaker, A., \& Makram, B. (2012). Modelling heavy tails and double long memory in North African stock market returns. The Journal of North African Studies, 17(2), 195-214. http://dx.doi.org/10.1080/13629387.2012.655068

Boudoukh, J., Richardson, M. P., \& Whitelaw, R. F. (1994). A tale of three schools: Insights on autocorrelations of short-horizon stock returns. The Review of Financial Studies, 7(3), 539-573. http://dx.doi.org/10.1093/rfs/7.3.539

Brock, W. A., Hsieh, D. A., \& LeBaron, B. (1991). Nonlinear Dynamics, Chaos, and Instability: Statistical Theory and Economic Evidence. Cambridge, MA: The MIT Press.

Brock, W., Lakonishok, J., \& LeBaron, B. (1992). Simple technical trading rules and the stochastic properties of stock returns. The Journal of Finance, 47(5), 1731-1764. http://dx.doi.org/10.1111/j.1540-6261.1992.tb04681.x

Cajueiro, D. O., \& Tabak, B. M. (2004). Evidence of long range dependence in Asian equity markets: The role of liquidity and market restrictions. Physica A, 342(3-4), 656-664. http://dx.doi.org/10.1016/j.physa.2004.05.034

Cajueiro, D. O., \& Tabak, B. M. (2005). Possible causes of long-range dependence in the Brazilian stock market. Physica A, 345(3-4), 635-645.

Campbell, J. Y., Lo, A. W., \& Mackinlay, A. C. (1996). The Econometrics of Financial Markets. Princeton, NJ: Princeton University Press.

Cavalcante, J., \& Assaf, A. (2002). Long-range dependence in the returns and volatility of the Brazilian stock market. Stock Market Manuscript, Rio de Janeiro.

Chen, S.-H. (2000). Lecture 7: Rescale range analysis and the Hurst exponent. Financial Economics (I), Department of Economics, National Chengchi University.

Chow, K. V., Pan, M.-S., \& Sakano, R. (1996). On the long-term or short-term dependence in stock prices: Evidence from international stock markets. Review of Quantitative Finance and Accounting, 6(2), $181-194$. http://dx.doi.org/10.1007/BF00367503

Cont, R. (2001). Empirical properties of asset returns: Stylized facts and statistical issues. Quantitative Finance, 1(2), 223-236. http://dx.doi.org/10.1080/713665670

Cowles, 3rd, A., \& Jones, H. E. (1937). Some a posteriori probabilities in stock market action. Econometrica, 5(3), 280-294. http://dx.doi.org/10.2307/1905515

Cox, J. C., \& Ross, S. A. (1976). The valuation of options for alternative stochastic processes. Journal of Financial Economics, 3(1-2), 145-166. http://dx.doi.org/10.1016/0304-405X(76)90023-4 
Elder, J., \& Serletis, A. (2007). On fractional integrating dynamics in the US stock market. Chaos, Solitons \& Fractals, 34(3), 777-781. http://dx.doi.org/10.1016/j.chaos.2006.04.004

Fama, E. F. (1965). The behavior of stock-market prices. Journal of Business, 38(1), 34-105. http://dx.doi.org/10.1086/294743

Fama, E. F. (1970). Efficient capital markets: A review of theory and empirical work. The Journal of Finance, 25(2), 383-417. http://dx.doi.org/10.2307/2325486

Fama, E. F. (1991). Efficient capital markets: II. The Journal of Finance, 46(5), 1575-1617. http://dx.doi.org/10.1111/j.1540-6261.1991.tb04636.x

Fama, E. F., \& French, K. R. (1988). Permanent and temporary components of stock prices. Journal of Political Economy, 96(2), 246-273. http://dx.doi.org/10.1086/261535

Goetzmann, W. N. (1993). Patterns in three centuries of stock market prices. The Journal of Business, 66(2), 249-270. http://dx.doi.org/10.1086/296603

Graham, J. R. (1999). Herding among investment newsletters: Theory and evidence. The Journal of Finance, 54(1), 237-268. http://dx.doi.org/10.1111/0022-1082.00103

Graham, J. R., \& Harvey, C. R. (1996). Market timing ability and volatility implied in investment newsletters asset allocation recommendations. Journal of Financial Economics, 42(3), $397-421$. http://dx.doi.org/10.1016/0304-405X(96)00878-1

Graham, J. R., \& Harvey, C. R. (1997). Grading the performance of market-timing newsletters. Financial Analysts Journal, 53(6), 54-66. http://dx.doi.org/10.2469/faj.v53.n6.2130

Grau-Carles, P. (2005). Tests of long memory: A bootstrap approach. Computational Economics, 25(1-2), 103113. http://dx.doi.org/10.1007/s10614-005-6277-6

Greene, M. T., \& Fielitz, B. D. (1977). Long-term dependence in common stock returns. Journal of Financial Economics, 4(3), 339-349. http://dx.doi.org/10.1016/0304-405X(77)90006-X

Grossman, S. J., \& Stiglitz, J. E. (1980). On the impossibility of informationally efficient markets. The American Economic Review, 70(3), 393-408.

Harrison, J. M., \& Kreps, D. M. (1979). Martingales and arbitrage in multiperiod securities markets. Journal of Economic Theory, 20(3), 381-408. http://dx.doi.org/10.1016/0022-0531(79)90043-7

Henry, Ó. T. (2002). Long memory in stock returns: Some international evidence. Applied Financial Economics, 12(10), 725-729. http://dx.doi.org/10.1080/09603100010025733

Hiemstra, C., \& Jones, J. D. (1997). Another look at long memory in common stock returns. Journal of Empirical Finance, 4(4), 373-401. http://dx.doi.org/10.1016/S0927-5398(96)00016-3

Hsieh, D. A. (1989). Testing for nonlinear dependence in daily foreign exchange rates. The Journal of Business, 62(3), 339-368. http://dx.doi.org/10.1086/296466

Huang, B.-N., \& Yang, C. W. (1999). An examination of long-term memory using the intraday stock returns. Technical Report 99-03, Clarion University of Pennsylvania, Clarion.

Hulbert, M. (2002). The Forbes/Hulbert investment letter survey. The Hulbert Financial Digest.

Hurst, H. E. (1951). Long-term storage capacity of reservoirs. Transactions of the American Society of Civil Engineers, 116, 770-799, 800-808.

Jaffe, J. F., \& Mahoney, J. M. (1999). The performance of investment newsletters. Journal of Financial Economics, 53(2), 289-307. http://dx.doi.org/10.1016/S0304-405X(99)00023-9

Jegadeesh, N. (1990). Evidence of predictable behavior of security returns. The Journal of Finance, 45(3), 881898. http://dx.doi.org/10.1111/j.1540-6261.1990.tb05110.x

Kang, S. H., Cheong, C., \& Yoon, S.-M. (2010). Contemporaneous aggregation and long-memory property of returns and volatility in the Korean stock market. Physica A, 389(21), 4844-4854. http://dx.doi.org/10.1016/j.physa.2010.06.040

Kim, M. J., Nelson, C. R., \& Startz, R. (1991). Mean reversion in stock prices? A reappraisal of the empirical 
evidence. The Review of Economic Studies, 58(3), 515-528. http://dx.doi.org/10.2307/2298009

Kumar, A., \& Pons, V. (2002). Behavior and performance of investment newsletters analysts. Working paper ysm275, Yale School of Management, New Haven, CT.

Lewellen, J. (2002). Momentum and autocorrelation in stock returns. The Review of Financial Studies, 15(2), 533-563. http://dx.doi.org/10.1093/rfs/15.2.533

Lim, K.-P., Brooks, R. D., \& Hinich, M. J. (2008). Nonlinear serial dependence and the weak-form efficiency of Asian emerging stock markets. Journal of International Financial Markets, Institutions and Money, 18(5), 527-544. http://dx.doi.org/10.1016/j.intfin.2007.08.001

Limam, I. (2003). Is long memory a property of thin stock markets? International evidence using arab countries. Review of Middle East Economics and Finance, 1(3), 251-266. http://dx.doi.org/10.1080/1475368032000158241

Llorente, G., Michaely, R., Saar, G., \& Wang, J. (2002). Dynamic volume-return relation of individual stocks. The Review of Financial Studies, 15(4), 1005-1047. http://dx.doi.org/10.1093/rfs/15.4.1005

Lo, A. W. (1991). Long-term memory in stock market prices. Econometrica, 59(5), 1279-1313. http://dx.doi.org/10.2307/2938368

Lo, A. W., \& MacKinlay, A. C. (1988). Stock market prices do not follow random walks: Evidence from a simple specification test. The Review of Financial Studies, 1(1), 41-66. http://dx.doi.org/10.1093/rfs/1.1.41

Lo, A. W., \& MacKinlay, A. C. (1990). When are contrarian profits due to stock market overreaction? The Review of Financial Studies, 3(2), 175-205. http://dx.doi.org/10.1093/rfs/3.2.175

Lo, A. W., \& MacKinlay, A. C. (1999). A Non-Random Walk Down Wall Street. Princeton, NJ: Princeton University Press.

Lobato, I. N., \& Savin, N. E. (1998). Real and spurious long-memory properties of stock-market data. Journal of Business \& Economic Statistics, 16(3), 261-268.

Longin, F. M. (1996). The asymptotic distribution of extreme stock market returns. The Journal of Business, 69(3), 383-408. http://dx.doi.org/10.1086/209695

Lucas, Jr, R. E. (1978). Asset prices in an exchange economy. Econometrica, 46(6), 1429-1445. http://dx.doi.org/10.2307/1913837

Lux, T. (1996). Long-term stochastic dependence in financial prices: Evidence from the German stock market. Applied Economics Letters, 3(11), 701-706. http://dx.doi.org/10.1080/135048596355691

Malkiel, B. (1992). Efficient market hypothesis. In Newman, P., Milgate, M., and Eatwell, J., editors, New Palgrave Dictionary of Money and Finance. Macmillan, London.

Mandelbrot, B. B. (1972). Statistical methodology for non-periodic cycles: From the covariance to R/S analysis. Annals of Economic and Social Measurement, 1, 259-290.

Metrick, A. (1999). Performance evaluation with transactions data: The stock selection of investment newsletters. The Journal of Finance, 54(5), 1743-1775. http://dx.doi.org/10.1111/0022-1082.00165

Mills, T. C. (1993). Is there long-term memory in UK stock returns? Applied Financial Economics, 3(4), $303-306$. http://dx.doi.org/10.1080/758534941

Mishra, R. K., Sehgal, S., \& Bhanumurthy, N. R. (2011). A search for long-range dependence and chaotic structure in Indian stock market. Review of Financial Economics, 20(2), 96-104. http://dx.doi.org/10.1016/j.rfe.2011.04.002

Mukherjee, I., Sen, C., \& Sarkar, A. (2011). Long memory in stock returns: Insights from the Indian market. The International Journal of Applied Economics and Finance, 5(1), 62-74. http://dx.doi.org/10.3923/ijaef.2011.62.74

Nath, G. C. (2001). Long memory and Indian stock market - an empirical evidence. National Stock Exchange of India Ltd., Mumbai.

Nawrocki, D. (1995). R/S analysis and long term dependence in stock market indices. Managerial Finance, 21(7), 
78-91. http://dx.doi.org/10.1108/eb018529

Neftci, S. N. (1991). Naive trading rules in financial markets and Wiener-Kolmogorov prediction theory: A study of "technical analysis". The Journal of Business, 64(4), 549-571. http://dx.doi.org/10.1086/296551

Oh, G., Kim, S., \& Eom, C. (2008). Long-term memory and volatility clustering in high-frequency price changes. Physica A, 387(5-6), 1247-1254. http://dx.doi.org/10.1016/j.physa.2007.08.061

Oh, G., Um, C.-J., \& Kim, S. (2006). Long-term memory and volatility clustering in daily and high-frequency price changes. arXiv:physics/0601174.

Panas, E. (2001). Estimating fractal dimension using stable distributions and exploring long memory through ARFIMA models in the Athens Stock Exchange. Applied Financial Economics, 11(4), $395-402$. http://dx.doi.org/10.1080/096031001300313956

Park, C.-H., \& Irwin, S. H. (2004). The profitability of technical analysis: A review. AgMAS Project Research Report 2004-04, University of Illinois at Urbana-Champaign, Urbana.

Rege, S., \& Martín, S. G. (2011). Portuguese stock market: A long-memory process? Business: Theory and Practice, 12(1), 75-84.

Roberts, H. (1967). Statistical versus clinical prediction of the stock market. Unpublished manuscript.

Rubinstein, M. (2001). Rational markets: Yes or no? The affirmative case. Financial Analysts Journal, 57(3), 15-29. http://dx.doi.org/10.2469/faj.v57.n3.2447

Sadique, S., \& Silvapulle, P. (2001). Long-term memory in stock market returns: International evidence. International Journal of Finance \& Economics, 6(1), 59-67. http://dx.doi.org/10.1002/ijfe.143

Samuelson, P. A. (1965). Proof that properly anticipated prices fluctuate randomly. Industrial Management Review, $6(2), 41-49$.

Scheinkman, J. A., \& LeBaron, B. (1989). Nonlinear dynamics and stock returns. The Journal of Business, 62(3), 311-337. http://dx.doi.org/10.1086/296465

Schwert, G. W. (2003). Anomalies and market efficiency. In Constantinides, G. M., Harris, M., and Stulz, R. M., editors, Handbook of the Economics of Finance: Volume 1B, Financial Markets and Asset Pricing, volume 21 of Handbooks in Economics, chapter 15, pp. 937-972. Elsevier North-Holland, Amsterdam.

Serletis, A., \& Rosenberg, A. A. (2009). Mean reversion in the US stock market. Chaos, Solitons \& Fractals, 40(4), 2007-2015. http://dx.doi.org/10.1016/j.chaos.2007.09.085

Sewell, M. (2011). History of the efficient market hypothesis. Research Note RN/11/04, University College London, London.

Tan, S.-H., Chong, L.-L., \& Yeap, P.-F. (2010). Long memory properties in stock prices: Evidence from the Malaysian stock market. European Journal of Economics, Finance and Administrative Sciences, 18, 77-84.

Tirole, J. (1982). On the possibility of speculation under rational expectations. Econometrica, 50(5), 1163-1182. http://dx.doi.org/10.2307/1911868

Tolvi, J. (2003a). Long memory and outliers in stock market returns. Applied Financial Economics, 13(7), 495502. http://dx.doi.org/10.1080/09603100210161983

Tolvi, J. (2003b). Long memory in a small stock market. Economics Bulletin, 7(3), 1-13.

Tóth, B., \& Kertész, J. (2006). Increasing market efficiency: Evolution of cross-correlations of stock returns. Physica A, 360(2), 505-515. http://dx.doi.org/10.1016/j.physa.2005.06.058

Willinger, W., Taqqu, M. S., \& Teverovsky, V. (1999). Stock market prices and long-range dependence. Finance and Stochastics, 3(1), 1-13. http://dx.doi.org/10.1007/s007800050049

Zhuang, Y., Green, C. J., \& Maggioni, P. (2000). The great rebound, the great crash, and persistence in British stock prices. Technical Report 00/11, Loughborough University, Loughborough. 